BMJ Open

Diabetes

Research

\& Care

\title{
Insomnia is associated with an increased risk of type 2 diabetes in the clinical setting
}

\author{
Erin S LeBlanc, Ning X Smith, Gregory A Nichols, Michael J Allison, \\ Gregory N Clarke
}

To cite: LeBlanc ES, Smith NX, Nichols GA, et al. Insomnia is associated with an increased risk of type 2 diabetes in the clinical setting. BMJ Open Diab Res Care 2018;6:e00604. doi:10.1136/ bmjdrc-2018-000604

Received 22 August 2018 Revised 31 0ctober 2018 Accepted 27 November 2018

\section{Check for updates}

\section{(c) Author(s) (or their} employer(s)) 2018. Re-use permitted under CC BY-NC. No commercial re-use. See rights and permissions. Published by BMJ.

Science Program Department, Kaiser Permanente Center for Health Research NW, Portland, Oregon, USA

Correspondence to Dr Gregory A Nichols; greg.nichols@kpchr.org

\section{ABSTRACT}

Objective To determine the possible association between insomnia and risk of type 2 diabetes mellitus (T2DM) in the naturalistic clinical setting.

Research design and methods We conducted a retrospective cohort study to examine the risk of developing T2DM among patients with pre-diabetes with and without insomnia. Participants with pre-diabetes (identified by a physician or via two laboratory tests) between January 1, 2007 and December 31, 2015 and without sleep apnea were followed until December 31, 2016. Patients were determined to have T2DM when two of the following occurred within a 2-year window: physician-entered outpatient T2DM diagnosis (International Classification of Diseases [ICD]-9 250.00; ICD-10 E11), dispensing of an antihyperglycemia agent, and hemoglobin A1c (A1c) $>6.5 \%$ (48 mmol/mol) or fasting plasma glucose (FPG) $>125 \mathrm{mg} / \mathrm{dL}$. One hospital inpatient stay with an associated T2DM diagnosis was also sufficient for classification of T2DM.

Results Our cohort consisted of 81233 persons with prediabetes, 24146 (29.7\%) of whom had insomnia at some point during the 4.3-year average observation period. After adjustment for traditional risk factors, those with insomnia were $28 \%$ more likely to develop T2DM than those without insomnia (HR 1.28; $95 \% \mathrm{Cl} 1.24$ to 1.33). The estimate was essentially unchanged after adjusting for baseline A1c level (HR 1.32; $95 \% \mathrm{Cl} 1.25$ to 1.40 ) or FPG (HR $1.28 ; 95 \% \mathrm{Cl}$ 1.23 to 1.33 )

Conclusions Insomnia imparts an increased risk of T2DM comparable with that conferred by traditional risk factors (eg, overweight, non-white race, cardiovascular risk factors). This association could have clinical importance because it suggests a new potentially modifiable risk factor that could be targeted to prevent diabetes.

\section{INTRODUCTION}

Type 2 diabetes mellitus (T2DM) is a significant public health burden. If current trends continue, one in three Americans will develop T2DM by $2050 .^{1}$ Insomnia is emerging as a possible modifiable risk factor in the development of T2DM. In short-term laboratory studies, experimentally induced sleep deprivation led to hyperglycemia, which was subsequently reversed with normal sleep restoration. ${ }^{2-9}$ These induced-insomnia

\section{Significance of this study}

What is already known about this subject?

- In short-term laboratory studies, experimentally induced sleep deprivation led to hyperglycemia, which was reversed with normal sleep restoration.

- Some epidemiologic studies have found that the quantity and quality of sleep are significant predictors of the risk of developing type 2 diabetes mellitus (T2DM).

What are the new findings?

- Our study adds to this literature by examining whether and confirming that a clinical diagnosis of insomnia is a risk factor for diabetes.

- By establishing an association between clinically recognized insomnia and T2DM risk, we have expanded the at-risk category to include those with clinically diagnosed insomnia, which can be more easily applied in the healthcare setting than relying on sleep questionnaires.

How might these results change the focus of research or clinical practice?

- Treatment of sleep problems holds promise as a strategy to prevent T2DM, but further research is needed to test its effectiveness.

studies have been necessarily limited to small samples and short duration and did not examine whether prolonged sleep disruption increased the risk of developing T2DM in otherwise healthy individuals. Relevant to this question, some, but not all, epidemiologic studies have found that the quantity and quality of sleep are significant predictors of the risk of developing T2DM. ${ }^{10}$ The specific causal mechanisms are as yet undetermined, but sleep loss is hypothesized to increase the risk of developing diabetes via multiple pathways, including loss of pancreatic $\beta$-cell function, ${ }^{11}$ altered adipokine profiles, ${ }^{12}$ increased activation of the sympathetic nervous system, ${ }^{13}$ increased inflammation, ${ }^{13}$ increased cortisol levels, ${ }^{14}$ increased food intake, weight gain, obesity, and decreased physical activity. ${ }^{1516}$ 
To further understand the association between insomnia and T2DM, we conducted a retrospective panel cohort study to examine the risk of developing T2DM among patients with pre-diabetes with and without insomnia. We hypothesized that the risk of T2DM would be higher among persons with insomnia, after controlling for other known or suspected T2DM risk factors.

\section{MATERIALS AND METHODS}

\section{Setting}

Kaiser Permanente Northwest (KPNW) is a not-for-profit, group-model integrated delivery system that provides comprehensive medical care to more than 600000 individuals in the metropolitan area around Portland, Oregon.

\section{Identification of cohort or patients with pre-diabetes}

KPNW uses healthcare utilization data to track and facilitate operations. An electronic medical record (EMR), in use since 1996, allows providers to record International Classification of Diseases (ICD) diagnosis codes at each patient contact and to update an electronic problem list, also with ICD codes. A single regional laboratory processes most KPNW outpatient laboratory tests, and the results are stored in a searchable database. A pharmacy is located at each medical clinic, and most members have a pharmacy benefit, ensuring almost complete capture of data on pharmaceutical dispenses. The EMR healthcare utilization data made it possible to determine patient eligibility for the study cohort. To be eligible for the study cohort, participants had to have had pre-diabetes (as defined by a physician diagnosis [ICD-9 790.29; ICD-10 R73.09] or two laboratory tests in the pre-diabetes range (fasting plasma glucose [FPG] from 100 to $125 \mathrm{mg} / \mathrm{dL}$ and/or hemoglobin A1c [A1c] from 5.70\% to $6.49 \%$ [39-47 mmol/mol]) between January 1, 2007 and December 31, 2015. Participants' baseline $\left(\mathrm{T}_{0}\right)$ was defined as the date of their first indicator of pre-diabetes. Participants had to be continuous members at least 1 year prior to $\mathrm{T}_{0}$ and 18 years or older at $\mathrm{T}_{0}$. Participants with obstructive sleep apnea (ICD-9 327.23; ICD-10 G47.33), sleep-disordered breathing (ICD-9 327.2X; ICD-10 G 47.30), restless leg syndrome (ICD-9 333.94; ICD-10 G25.81), and periodic leg movement disorder (ICD-9 327.5; ICD 10 G47.61) up to 1 year prior to $\mathrm{T}_{0}$, or with T2DM (as described below) or bariatric surgery at any prior date were excluded.

\section{Follow-up of patients and identification of the development of T2DM}

We followed participants with pre-diabetes from $\mathrm{T}_{0}$ until the earliest of the following events occurred: T2DM diagnosis, loss of Kaiser Permanente membership ( $>3$ months break in coverage), death, bariatric surgery, or end of study follow-up (December 31, 2016). Patients were determined to have a T2DM diagnosis when two of the following occurred within a 2-year window: physician-entered outpatient T2DM diagnosis (ICD-9 250.00; ICD-10
E11), dispensing of an antihyperglycemia agent, A1c $>6.5 \%(48 \mathrm{mmol} / \mathrm{mol})$, and/or FPG $>125 \mathrm{mg} / \mathrm{dL}$. One hospital inpatient stay with an associated T2DM diagnosis was also sufficient for classification of T2DM. ${ }^{17}$

\section{Identification of insomnia and covariates}

Participants were determined to have insomnia if they had a physician-entered diagnosis of insomnia (ICD-9 $307.40, \quad 307.45-9, \quad 780.50, \quad 780.53, \quad 780.55-9$, V69.4, $307.41,307.42,780.51,780.52$; ICD-10 F51.01) prior to the diagnosis of diabetes and/or used one or more medications predominantly prescribed for sleep problems in this health plan (eg, trazodone, eszopiclone, zaleplon, or zolpidem) in the 12 months prior to the diagnosis of diabetes.

We also collected data on potential covariates that might influence the development or detection of T2DM: age, body mass index (BMI), sex, race (black, Asian, white, other), ethnicity (Hispanic, not Hispanic), history of congestive heart failure (CHF) and myocardial infarction, hypertension (measured as $\geq 140 / 90$ or by diagnosis code), elevated triglyceride levels $(>150 \mathrm{mg} / \mathrm{dL})$, and low high-density lipoprotein (HDL) levels $(<40 \mathrm{mg} / \mathrm{dL}) .{ }^{18}$

\section{Statistical analyses}

We calculated summary statistics describing the characteristics of eligible participants stratified by insomnia status. Continuous variables were summarized as mean $\pm \mathrm{SD}$ and were compared using t-test (for data that were normally distributed) or Mann-Whitney U test (for data that were not normally distributed). Categorical variables were expressed as frequency and percentages and were compared using $\chi^{2}$ test. We used multivariate time-varying covariates Cox regression models to estimate HRs and $95 \%$ CIs for the association between the risk of developing T2DM and insomnia, adjusting for various confounders. Insomnia was treated as the timevarying covariate as study participants could experience insomnia at any time during the follow-up period. Analyses were conducted using the SAS V.9.4 software.

\section{RESULTS}

\section{Baseline characteristics}

Our cohort consisted of 81233 persons who had pre-diabetes between January 1, 2007 and December 31, 2015 and had data for all baseline covariates; 24146 (29.7\%) were classified as having insomnia at some point during the observation period (but before diagnosis of T2DM). The average observation window was 4.3 (SD 2.8) years. Participants had a mean age of 57.5 (SD 13.6) years at the time of initial identification with pre-diabetes (table 1 ). Compared with participants without insomnia indications, those with insomnia were older and were more likely to be above normal weight, female, white, not Hispanic, and current or previous smokers, and to have a history of CHF, hypertension, elevated triglycerides $(\geq 150 \mathrm{mg} / \mathrm{dL})$, and low HDL $(<40 \mathrm{mg} / \mathrm{dL})$ (all $\mathrm{p}<0.001)$. Consistent with the American Diabetes Association guidelines, our 
Table 1 Baseline characteristics

\begin{tabular}{|c|c|c|c|c|}
\hline & $\begin{array}{l}\text { Total } \\
\mathrm{n}=81233\end{array}$ & $\begin{array}{l}\text { Insomnia } \\
\mathrm{n}=24146\end{array}$ & $\begin{array}{l}\text { No insomnia } \\
\mathrm{n}=57087\end{array}$ & $P$ value \\
\hline Age & & & & $<0.0001$ \\
\hline Mean (SD) & $57.5(13.6)$ & $58.4(13.1)$ & $57.1(13.8)$ & \\
\hline $\mathrm{BMI}, \mathrm{kg} / \mathrm{m}^{2}, \mathrm{n}(\%)$ & & & & $<0.0001$ \\
\hline$<25$ & $14238(17.5)$ & $4013(16.6)$ & 10225 (17.9) & \\
\hline$\geq 25$ to 29.9 & $26694(32.9)$ & $7417(30.7)$ & 19277 (33.8) & \\
\hline$\geq 30$ to 39.9 & 31943 (39.3) & 9699 (40.2) & 22244 (39.0) & \\
\hline$\geq 40$ & 358 (10.3) & 3017 (12.5) & $5341(9.4)$ & \\
\hline Sex, n (\%) & & & & $<0.0001$ \\
\hline Female & 43562 (53.6) & $13547(56.1)$ & 30015 (52.6) & \\
\hline Male & 37671 (46.4) & $10599(43.9)$ & 27072 (47.4) & \\
\hline Race, n (\%) & & & & $<0.0001$ \\
\hline White & 65803 (81.0) & 20761 (86.0) & 45042 (78.9) & \\
\hline Asian & $3979(4.9)$ & $724(3.0)$ & $3255(5.7)$ & \\
\hline Black & $2208(2.7)$ & $572(2.4)$ & $1636(2.9)$ & \\
\hline Other & 9243 (11.4) & $2089(8.7)$ & 7154 (12.5) & \\
\hline Ethnicity, n (\%) & & & & $<0.0001$ \\
\hline Not Hispanic & $76946(94.7)$ & $23176(96.0)$ & 23176 (94.2) & \\
\hline Hispanic & $4287(5.3)$ & $970(4.0)$ & $3317(5.8)$ & \\
\hline Smoking status, n (\%) & & & & $<0.0001$ \\
\hline Never & $43202(53.2)$ & $11778(48.8)$ & 31424 (55.0) & \\
\hline Current & $10063(12.4)$ & $3172(13.1)$ & $6891(12.1)$ & \\
\hline Previous & $27519(33.9)$ & $9084(37.6)$ & 18435 (32.3) & \\
\hline Unknown & $449(0.6)$ & $112(0.5)$ & $337(0.6)$ & \\
\hline Congestive heart failure, $\mathrm{n}(\%)$ & & & & $<0.0001$ \\
\hline No & 79915 (98.4) & $23613(97.8)$ & 56302 (98.6) & \\
\hline Yes & $1318(1.6)$ & $533(2.2)$ & $785(1.4)$ & \\
\hline Myocardial infarction, n (\%) & & & & 0.07 \\
\hline No & 80639 (99.3) & $23949(99.2)$ & 56690 (99.3) & \\
\hline Yes & $594(0.7)$ & $197(0.8)$ & $397(0.7)$ & \\
\hline Hypertension, n (\%) & & & & $<0.0001$ \\
\hline No & 35159 (43.3) & $9346(38.7)$ & $25813(45.2)$ & \\
\hline Yes & $46074(56.7)$ & $14800(61.3)$ & $31274(54.8)$ & \\
\hline $\begin{array}{l}\text { Elevated triglycerides ( } \geq 150 \mathrm{mg} / \mathrm{dL}) \text {, } \\
n(\%)\end{array}$ & & & & $<0.0001$ \\
\hline No & 38478 (47.4) & $10976(45.5)$ & 27502 (48.2) & \\
\hline Yes & $42755(52.6)$ & $13170(54.5)$ & $29858(51.8)$ & \\
\hline Low HDL (<40 mg/dL), n (\%) & & & & $<0.0001$ \\
\hline No & $4929(60.7)$ & $14166(58.7)$ & $35128(61.5)$ & \\
\hline Yes & 31939 (39.3) & $9980(41.3)$ & 21959 (38.5) & \\
\hline Hemoglobin A1c & $n=45261$ & $n=12485$ & $n=32776$ & $<0.0001$ \\
\hline$\%$, mean $(\mathrm{SD})$ & $5.8(0.25)$ & $5.8(0.26)$ & $5.9(0.25)$ & \\
\hline mmol/mol, mean (SD) & $40(2.73)$ & $40(2.84)$ & $41(2.73)$ & \\
\hline Fasting glucose & $n=50443$ & $n=16714$ & $n=33729$ & 0.87 \\
\hline mg/dL, mean (SD) & $102.4(9.62)$ & $102.4(9.45)$ & $102.4(9.70)$ & \\
\hline
\end{tabular}

$B M I$, body mass index; HDL, high-density lipoprotein. 
Table 2 Risk of developing T2DM according to insomnia status

\begin{tabular}{|c|c|c|c|}
\hline \multirow[b]{2}{*}{ Risk factor } & \multirow{2}{*}{$\begin{array}{l}\begin{array}{l}\text { Baseline model } \\
(\mathrm{n}=79608)\end{array} \\
\mathrm{HR}(95 \% \mathrm{Cl})\end{array}$} & \multirow{2}{*}{$\begin{array}{l}\text { Model adjusted for } \\
\text { baseline A1c } \\
(\mathrm{n}=45 \mathrm{267})\end{array}$} & \multirow{2}{*}{$\begin{array}{l}\text { Model adjusted for } \\
\text { baseline FPG } \\
\text { (n=50 443) } \\
\text { HR }(95 \% \mathrm{Cl})\end{array}$} \\
\hline & & & \\
\hline Insomnia & 1.28 (1.24 to 1.33$)$ & $1.32(1.25$ to 1.40$)$ & $1.28(1.23$ to 1.33$)$ \\
\hline Baseline age (per 10-year increment) & 1.11 (1.09 to 1.12$)$ & 1.04 (1.02 to 1.07$)$ & $1.08(1.07$ to 1.10$)$ \\
\hline \multicolumn{4}{|l|}{ Baseline BMI (vs $25 \mathrm{~kg} / \mathrm{m}^{2}$ ) } \\
\hline$\geq 25$ to 29.9 & 1.21 (1.13 to 1.28$)$ & 1.14 (1.04 to 1.25$)$ & $1.11(1.03$ to 1.19$)$ \\
\hline$\geq 30$ to 39.9 & 1.89 (1.78 to 2.01$)$ & $1.64(1.50$ to 1.79$)$ & 1.61 (1.51 to 1.73$)$ \\
\hline$\geq 40$ & 3.12 (2.91 to 3.35$)$ & 2.50 (2.25 to 2.77$)$ & 2.45 (2.26 to 2.65$)$ \\
\hline Male sex & 1.02 (0.98 to 1.05$)$ & 1.13 (1.08 to 1.20$)$ & 0.90 (0.86 to 0.93$)$ \\
\hline \multicolumn{4}{|l|}{ Race (vs white) } \\
\hline Asian & 1.85 (1.71 to 2.01$)$ & $1.32(1.17$ to 1.50$)$ & $1.98(1.81$ to 2.17$)$ \\
\hline Black & 1.36 (1.24 to 1.49$)$ & 0.90 (0.79 to 1.04$)$ & 1.66 (1.49 to 1.86$)$ \\
\hline Other & 1.27 (1.20 to 1.35$)$ & 1.14 (1.03 to 1.25$)$ & 1.30 (1.21 to 1.39$)$ \\
\hline Hispanic & $1.11(1.02$ to 1.21$)$ & $1.03(0.90$ to 1.17$)$ & 1.15 (1.04 to 1.27$)$ \\
\hline \multicolumn{4}{|l|}{ Smoking status (vs never) } \\
\hline Current & 1.36 (1.29 to 1.43$)$ & 1.26 (1.17 to 1.37$)$ & 1.29 (1.22 to 1.37$)$ \\
\hline Previous & 1.09 (1.05 to 1.13$)$ & 1.18 (1.12 to 1.25$)$ & 1.05 (1.01 to 1.10$)$ \\
\hline Unknown & 1.06 (0.86 to 1.31$)$ & $1.22(0.85$ to 1.77$)$ & 0.95 (0.75 to 1.20$)$ \\
\hline Congestive heart failure & 1.76 (1.58 to 1.95$)$ & 1.55 (1.31 to 1.82$)$ & 1.69 (1.50 to 1.91$)$ \\
\hline Myocardial infarction & $1.22(1.03$ to 1.44$)$ & $1.48(1.17$ to 1.88$)$ & 1.26 (1.04 to 1.53$)$ \\
\hline Hypertension & 1.27 (1.23 to 1.32$)$ & 1.32 (1.25 to 1.40$)$ & 1.19 (1.14 to 1.24$)$ \\
\hline Low HDL & 1.35 (1.30 to 1.39$)$ & 1.32 (1.25 to 1.39$)$ & 1.29 (1.24 to 1.34$)$ \\
\hline Elevated triglycerides & 1.14 (1.10 to 1.18$)$ & 1.08 (1.02 to 1.14$)$ & $1.19(1.14$ to 1.24$)$ \\
\hline Baseline A1c (per $0.1 \%$ or $1 \mathrm{mmo} / \mathrm{mol}$ increase) & NA & $1.26(1.25$ to 1.27$)$ & NA \\
\hline Fasting plasma glucose (per $10 \mathrm{mg} / \mathrm{dL}$ increase) & NA & NA & 1.65 (1.61 to 1.68$)$ \\
\hline
\end{tabular}

BMI, body mass index; FPG, fasting plasma glucose; HDL, high-density lipoprotein; NA, not applicable; T2DM, type 2 diabetes mellitus.

health system diagnoses pre-diabetes and diabetes with A1c or FPG levels; based on this, 45267 (55.7\%) persons had A1c levels and 50443 (62.1\%) had FPG at or prior to their pre-diabetes diagnosis. In this cohort, the mean A1c at baseline was $5.8 \%(40 \mathrm{mmol} / \mathrm{mol})$ in those with insomnia vs $5.9 \%(41 \mathrm{mmol} / \mathrm{mol})$ in those without; FPG was $102.4 \mathrm{mg} / \mathrm{dL}$ in both groups.

\section{Risk of developing T2DM according to insomnia status and other traditional risk factors}

A total of $14626(18.0 \%)$ of the sample developed T2DM over an average of 4.3 years of follow-up. Of those with insomnia, $4564(18.9 \%)$ developed T2DM, compared with $10 \quad 062(17.6 \%)$ of those without insomnia $(\mathrm{p}<0.0001)$. In a multivariable model adjusting for traditional T2DM risk factors (age, BMI, sex, race, ethnicity, and history of CHF or myocardial infarction, hypertension, high triglycerides, low HDL, and smoking status), those with insomnia were $28 \%$ more likely to develop T2DM than those without insomnia (HR 1.28; 95\% CI 1.24 to 1.33) (table 2). As expected, traditional risk factors including older age, higher BMI, non-white race,
Hispanic ethnicity, current or previous smoking, history of CHF, history of myocardial infarction, hypertension, elevated triglycerides, and low HDL were also associated with an increased risk of developing T2DM. When we conducted sensitivity analyses, adding baseline A1c values $(\mathrm{n}=45267)$ and FPG levels $(\mathrm{n}=50443)$ to the model, the HR associated with insomnia was essentially unchanged (HR 1.32; 95\% CI 1.25 to 1.40 and HR 1.28; 95\% CI 1.23 to 1.33 , respectively).

\section{DISCUSSION}

In our study of 81233 persons with pre-diabetes, we found that participants with insomnia had about a $30 \%$ increased risk of developing T2DM even after adjusting for traditional risk factors including age, BMI, race, ethnicity, and cardiovascular risk factors. Because of the study's large size and because it was conducted in a real-world healthcare system, it adds important information to the growing body of literature suggesting the potentially important influence of sleep disruption on increased T2DM risk. 
The degree of increased risk we report is similar to that conferred by traditional risk factors, such as being overweight or of minority (non-white) race or Hispanic ethnicity, or by cardiovascular risk factors such as hypertension, elevated triglycerides, and low HDL. This association could have clinical importance because it suggests a new risk factor that is potentially modifiable and could be targeted in the diabetes prevention effort unlike unmodifiable risk factors such as age, race, and ethnicity.

While current interventions (weight loss and/or exercise interventions) to address conventional T2DM risk factors such as high BMI or sedentary lifestyle can be successful, they are often difficult to implement because of low participant motivation, high dropout rates and, in the case of weight loss programs, an often-delayed effect of the intervention and high risk of return of excess weight. ${ }^{19}$ In contrast, behavioral insomnia treatments are relatively brief and effective, are relatively easy to implement, and yield immediate positive benefit. ${ }^{20-22}$ Further, sleep-deprived patients are typically very motivated to restore good-quality sleep, in part because restoration of normal sleep is intrinsically rewarding.

Our findings are consistent with experimental work in which researchers disrupt sleep in healthy volunteers. Such studies find that inadequate sleep duration (typically 4-5 hours per night for a 1-day to 14-day period) and disruption of sleep architecture (by circadian misalignment with resultant changes in rapid eye movement (REM) distribution) result in hyperglycemia and insulin resistance, which is reversed when sleep returns to normal. ${ }^{2-9}$ Our study's findings are also consistent with previous epidemiologic studies which have found a 28\%-84\% increased risk of T2DM in those with short sleep duration or sleep difficulties. ${ }^{1023}$

Our study adds to this literature by examining T2DM risk in participants with a clinical diagnosis of insomnia; previous cohorts have used sleep questionnaires and examined specific elements of sleep (ie, duration and sleep initiation). By examining the association between clinically recognized insomnia and T2DM risk, we have expanded the at-risk category to include those with clinical insomnia, which can be more easily applied in the healthcare setting than relying on sleep questionnaires.

There are several possible reasons why poor sleep might increase the risk of T2DM. Experimental sleep deprivation and epidemiologic studies suggest that disrupted or short-duration sleep could impair the profile of peptides that mediate energy homeostasis (eg, leptin, ghrelin, adiponectin), leading to increased appetite, including cravings for calorie-dense, high-carbohydrate food, and ultimately insulin resistance. ${ }^{12}$ Other studies show that persons subjected to short-term experimental sleep deprivation and those with longterm short-sleep duration or sleep disturbances have elevated salivary and serum cortisol levels, particularly in the evening, when levels are normally quite low. ${ }^{14}$ Elevated cortisol levels are associated with increased central fat distribution, which is strongly associated with insulin resistance. ${ }^{24}$ Increased inflammation and sympathetic activation could also contribute to the association between sleep disruption and diabetes risk. Both are activated with sleep disruption, and activation of both systems has been tied to insulin resistance and eventually T2DM. ${ }^{13}{ }^{25-27}$ Insomnia has also been shown to accelerate loss of $\beta$-cell function and increase $\beta$-cell apoptosis with increased loss of $\beta$-cell mass in laboratory models. ${ }^{11}$ Finally, the fatigue associated with sleep loss may contribute to decreased amount and intensity of physical activity, which may contribute to the development of T2DM. ${ }^{15}$

This study has several strengths, including the large sample size with long follow-up and the use of multiple data sources (ICD-9 and ICD-10 codes, laboratory testing, and medication dispensing) to diagnose exposure and outcome data. However, the study is limited by the shortcomings of observational research. For example, measured insomnia may be the consequence of other unmeasured and thus uncontrolled factors (eg, work or personal stress, chronic pain). Further, all classifications of T2DM and insomnia were based solely on diagnoses, lab results, or medication dispenses recorded on the EMR, eroding our ability to discern the relationship between the two conditions. In particular, the prevalence of insomnia is likely underestimated in this cohort because sleep disorders are often underdiagnosed and/or insomnia symptoms are attributed to other conditions. ${ }^{28}$

T2DM is a major contributor to poor health and early death, ${ }^{29}$ and additional strategies to prevent diabetes are greatly needed. Our research suggests that behavioral treatment of insomnia deserves further study as a way to decrease T2DM risk. If sleep treatment can be added to the armamentarium for preventing the devastating disease of T2DM, the health of millions of people could be improved.

Acknowledgements We are grateful to Cassandra Angus for manuscript preparation and Katie Essick for editorial assistance.

Contributors ESL wrote the manuscript. NSS researched the data and reviewed/ edited the manuscript. GAN reviewed/edited the manuscript. MJA researched the data and reviewed/edited the manuscript. GNC reviewed/edited the manuscript. ESL takes responsibility for the content of the article.

Funding Funding was through an internal Kaiser Permanente research grant.

Competing interests ESL has had unrelated funding from Merck in the last years. GAN has unrelated grant funding from Boehringer-Ingelheim, Merck \& $\mathrm{C}$, Sanofi, Janssen Pharmaceuticals and Amarin.

Patient consent for publication Not required.

Ethics approval The study was reviewed and approved by the Kaiser Permanente Institutional Review Board.

Provenance and peer review Not commissioned; externally peer reviewed.

Data sharing statement № additional data are available.

Open access This is an open access article distributed in accordance with the Creative Commons Attribution Non Commercial (CC BY-NC 4.0) license, which permits others to distribute, remix, adapt, build upon this work non-commercially, and license their derivative works on different terms, provided the original work is properly cited, appropriate credit is given, any changes made indicated, and the use is non-commercial. See: http://creativecommons.org/licenses/by-nc/4.0 


\section{REFERENCES}

1. Centers for Disease Control and Prevention. Diabetes report card 2014. Atlanta GA: Centers for Disease Control and Prevention US Dept of Health and Human Services, 2015.

2. Spiegel K, Leproult R, Van Cauter E. Impact of sleep debt on metabolic and endocrine function. The Lancet 1999;354:1435-9.

3. van Leeuwen WMA, Hublin C, Sallinen M, et al. Prolonged sleep restriction affects glucose metabolism in healthy young men. Int $J$ Endocrinol 2010;2010:1-7.

4. Stamatakis KA, Punjabi NM. Effects of sleep fragmentation on glucose metabolism in normal subjects. Chest 2010;137:95-101.

5. Buxton OM, Pavlova M, Reid EW, et al. Sleep restriction for 1 week reduces insulin sensitivity in healthy men. Diabetes 2010;59:2126-33.

6. Nedeltcheva AV, Kessler L, Imperial J, et al. Exposure to recurrent sleep restriction in the setting of high caloric intake and physical inactivity results in increased insulin resistance and reduced glucose tolerance. J Clin Endocrinol Metab 2009;94:3242-50.

7. Benedict C, Hallschmid M, Lassen A, et al. Acute sleep deprivation reduces energy expenditure in healthy men. Am J Clin Nutr 2011;93:1229-36.

8. Cedernaes J, Lampola L, Axelsson EK, et al. A single night of partial sleep loss impairs fasting insulin sensitivity but does not affect cephalic phase insulin release in young men. J Sleep Res 2016;25:5-10.

9. Rao MN, Neylan TC, Grunfeld C, et al. Subchronic sleep restriction causes tissue-specific insulin resistance. J Clin Endocrinol Metab 2015;100:1664-71.

10. St-Onge M-P, Grandner MA, Brown D, et al. Sleep duration and quality: impact on lifestyle behaviors and cardiometabolic health: a scientific statement from the American heart association. Circulation 2016;134:e367-86.

11. Gale JE, Cox HI, Qian J, et al. Disruption of circadian rhythms accelerates development of diabetes through pancreatic beta-cell loss and dysfunction. J Biol Rhythms 2011;26:423-33.

12. Spiegel $K$, Leproult $R$, L'hermite-Balériaux $M$, et al. Leptin levels are dependent on sleep duration: relationships with sympathovagal balance, carbohydrate regulation, cortisol, and thyrotropin. J Clin Endocrinol Metab 2004;89:5762-71.

13. Irwin M, Clark C, Kennedy B, et al. Nocturnal catecholamines and immune function in insomniacs, depressed patients, and control subjects. Brain Behav Immun 2003;17:365-72.

14. Leproult R, Copinschi G, Buxton O, et al. Sleep loss results in an elevation of cortisol levels the next evening. Sleep 1997;20:865-70.
15. Bromley LE, Booth JN, Kilkus JM, et al. Sleep restriction decreases the physical activity of adults at risk for type 2 diabetes. Sleep 2012;35:977-84.

16. Patel SR, Hu FB. Short sleep duration and weight gain: a systematic review. Obesity 2008;16:643-53.

17. Nichols GA, Schroeder EB, Karter AJ, et al. Trends in diabetes incidence among 7 million insured adults, 2006-2011: the SUPREME-DM project. Am J Epidemiol 2015;181:32-9.

18. Nichols GA, Brown JB. Validating the Framingham offspring study equations for predicting incident diabetes mellitus. Am J Manag Care 2008;14:574-80.

19. Leblanc ES, O'Connor E, Whitlock EP, et al. Effectiveness of primary care-relevant treatments for obesity in adults: a systematic evidence review for the U.S. preventive services task force. Ann Intern Med 2011;155:434-47.

20. Riemann D, Baglioni C, Bassetti C, et al. European guideline for the diagnosis and treatment of insomnia. J Sleep Res 2017;26:675-700.

21. Brasure M, Fuchs E, MacDonald R, et al. Psychological and behavioral interventions for managing insomnia disorder: an evidence report for a clinical practice guideline by the American college of physicians. Ann Intern Med 2016;165:113-24.

22. Edinger JD, Wohlgemuth WK, Radtke RA, et al. Dose-response effects of cognitive-behavioral insomnia therapy: a randomized clinical trial. Sleep 2007;30:203-12.

23. Kowall B, Lehnich AT, Strucksberg KH, et al. Associations among sleep disturbances, nocturnal sleep duration, daytime napping, and incident prediabetes and type 2 diabetes: the Heinz Nixdorf recall study. Sleep Med 2016;21:35-41.

24. Champaneri S, Xu X, Carnethon MR, et al. Diurnal salivary cortisol is associated with body mass index and waist circumference: the multiethnic study of atherosclerosis. Obesity 2013;21:E56-63.

25. Xu H, Barnes GT, Yang Q, et al. Chronic inflammation in fat plays a crucial role in the development of obesity-related insulin resistance. $J$ Clin Invest 2003;112:1821-30.

26. Wieser V, Moschen AR, Tilg $\mathrm{H}$. Inflammation, cytokines and insulin resistance: a clinical perspective. Archivum Immunologiae et Therapiae Experimentalis 2013;61:119-25.

27. Zinman B, Hanley AJ, Harris SB, et al. Circulating tumor necrosis factor-alpha concentrations in a native Canadian population with high rates of type 2 diabetes mellitus. J Clin Endocrinol Metab 1999;84:272-8

28. Ting L, Malhotra A. Disorders of sleep: an overview. Primary Care: Clinics in Office Practice 2005;32:305-18.

29. Tancredi M, Rosengren A, Svensson AM, et al. Excess mortality among Persons with Type 2 diabetes. N Engl J Med 2015;373:1720-32 